\title{
Avaliação da qualidade do leite de propriedades da região do Vale do Taquari no estado do Rio Grande do Sul
}

\author{
Evaluation of milk's quality from properties in the region of Vale do Taquari in Rio Grande do Sul State
}

Karen Apellanis Borges ${ }^{1}$, Simone Reichert ${ }^{1}$, Maira Balbinotti Zanela ${ }^{2} \&$ Vivian Fischer ${ }^{3}$

\begin{abstract}
RESUMO
A melhoria da qualidade do leite é um grande desafio para o setor leiteiro, tendo em vista que uma matéria prima de boa qualidade resulta num maior rendimento e qualidade dos derivados lácteos produzidos, trazendo benefícios para a indústria e para o consumidor. A análise da composição (teor de gordura e proteína bruta), a contagem de células somáticas (CCS) e a contagem bacteriana total (CBT) são instrumentos importantes na avaliação da qualidade do leite. O Ministério da Agricultura, Pecuária e Abastecimento implantou a Instrução Normativa 51/2002, que estabeleceu parâmetros para os componentes do leite. $\mathrm{O}$ objetivo deste trabalho foi verificar a situação da qualidade do leite na região do Vale do Taquari, sua variação ao longo do ano e sua adequação aos parâmetros da IN51. O estudo foi realizado no período de agosto de 2006 a agosto de 2007 (13 meses). Foram coletadas amostras de leite de 11 propriedades selecionadas, totalizando 143 amostras. Foram realizadas as análises de: CCS, CBT e composição do leite (teores de gordura e proteína bruta). Os valores médios das análises realizadas foram: gordura - 3,34\%, proteína bruta - 3,09\%, CCS - 6,0x10 $0^{5}$ células $/ \mathrm{mL}$ e CBT - 1,07x10 UFC/mL. Com relação aos padrões da IN51, encontravam-se fora dos padrões estabelecidos para gordura, proteína bruta, CCS e CBT, respectivamente 9,$79 ; 7,69 ; 14,69 \%$ e $29,37 \%$ das amostras. A composição química e a CCS do leite analisado, na região do Vale do Taquari, demonstraram a boa qualidade da matéria prima. A contagem bacteriana total foi o fator limitante para a adequação do leite à IN51.
\end{abstract}

Descritores: contagem bacteriana total, contagem células somáticas, gordura, proteína bruta do leite, Instrução Normativa 51.

\section{ABSTRACT}

Improving the quality of milk is a great challenge for the dairy industry, since that a raw material of good quality results in a higher yield and quality of milk products produced, bringing benefits to industry and consumers. The analysis of the composition (fat content and crude protein), the somatic cell count (SCC) and total bacterial count (TBC) are important tools in assessing the quality of milk. The Ministry of Agriculture, Livestock and Supply deployed the Normative Instruction 51/2002, which established parameters for the components of milk. The aim of this study was to assess the situation of milk quality in the Vale do Taquari, its variation over the year and its appropriateness to the parameters of the IN51. The study was conducted from August 2006 to August 2007 (13 months). Milk samples were collected from 11 selected properties, totaling 143 samples. Were performed the analysis of: SCC, TBC and milk composition (fat levels and crude protein). The average values of the tests conducted were: fat $-3.34 \%$, crude protein $-3.09 \%$, CCS $-6.0 \times 10^{5}$ cells $/ \mathrm{mL}$ and TBC $-1.07 \times 10^{6} \mathrm{CFU} / \mathrm{mL}$. With regard to standards of the IN51, were outside the established standards for fat, crude protein, SCC and TBC, respectively $9.79,7.69,14.69 \%$ and $29.37 \%$ of the samples. The chemical composition of milk and SCC discussed, in the Valley of Taquari, demonstrated the good quality of raw materials. The total bacterial count was the limiting factor for the adequacy of the milk to IN 51.

Keywords: somatic cell count, total bacterial count, fat, crude protein, Normative Instruction 51.

${ }^{1}$ Programa de Pós-graduação em Ciências Veterinárias (PPGCV), Universidade Federal do Rio Grande do Sul (UFRGS) - Porto Alegre, RS/Brasil. ${ }^{2}$ Faculdade de Medicina Veterinária (FaVet), UFRGS. ${ }^{3}$ Faculdade de Agronomia-UFRGS. CORRESPONDÊNCIA: M B. Zanela [maira.zanela@ufrgs.br ; Fax: +55 (51) 3308 7305]. 


\section{INTRODUÇÃO}

O segmento de produção de leite é um dos mais importantes do Brasil, devido a sua importância sócioeconômica, mas a qualidade da matéria-prima é um grande entrave ao desenvolvimento tecnológico dos laticínios. Por isso, algumas empresas implantaram programas de pagamento do leite por qualidade $[1,12]$. Dentre os critérios mais freqüientemente utilizados para pagamento diferenciado estão os teores de gordura e proteína, a contagem de células somáticas e a contagem bacteriana total.

Segundo a Instrução Normativa 51, os teores mínimos estabelecidos para gordura, proteína bruta e sólidos desengordurados são: 3,0; 2,9 e 8,4\%, respectivamente [5]. Com relação à contagem de células somáticas (CCS) e contagem bacteriana total (CBT), na região Sul, o limite máximo estabelecido inicialmente foi de $1 \times 10^{6}$ células $/ \mathrm{mL}$ e $1 \times 10^{6} \mathrm{UFC} / \mathrm{mL}$, respectivamente, de julho de 2005 a julho de 2008. De julho de 2008 a julho de 2011, o limite é de 7,5x $10^{5}$ células $/ \mathrm{mL}$ e 7,5x $10^{5} \mathrm{UFC} / \mathrm{mL}$, e após esse período o máximo estabelecido será de $4 \times 10^{5}$ células $/ \mathrm{mL}$ e $3 \times 10^{5} \mathrm{UFC} / \mathrm{mL}$, respectivamente.

O Brasil deve adequar-se à IN51 para produzir leite e derivados de qualidade, elevando suas exportações, além de atender às crescentes exigências do mercado consumidor interno [8]. Dessa forma será possível melhorar as condições de pagamento ao produtor, que deverá receber segundo a qualidade da matéria-prima. O primeiro passo é compilar a maior quantidade de dados possíveis, referente a um determinado período e região, auxiliando a indústria nesse processo [10].

O objetivo desse trabalho foi avaliar a qualidade do leite na região do Vale do Taquari e comparar com os padrões estabelecidos pela Instrução Normativa 51.

\section{MATERIAIS E MÉTODOS}

O presente estudo foi realizado na região do Vale do Taquari, RS, no período de agosto de 2006 a agosto de 2007 (13 meses). Foram coletados os dados mensais de produção de leite mensal/proprie-dade, composição do leite, contagem de células somá-ticas e contagem bacteriana total de 11 propriedades de leite selecionadas. As propriedades abrangeram baixo, médio e alto volume de leite entregue. As propriedades possuíam predominantemente vacas da raça Holan-desa. Após a ordenha, o leite dos animais era misturado e armazenado em tanques de refrigeração até o momento da coleta do leite pelo transportador.

As amostras foram coletadas mensalmente e enviadas ao laboratório da Universidade de Passo Fundo para realização da contagem de células somáticas e contagem bacteriana por citometria de fluxo; e composição do leite (teores de gordura e proteína bruta) por radiação infravermelha. No total foram analisadas 143 amostras de leite.

Os dados foram tabulados e submetidos à estatística descritiva. Os valores foram analisados e comparados aos padrões estabelecidos pela Instrução Normativa 51 [5].

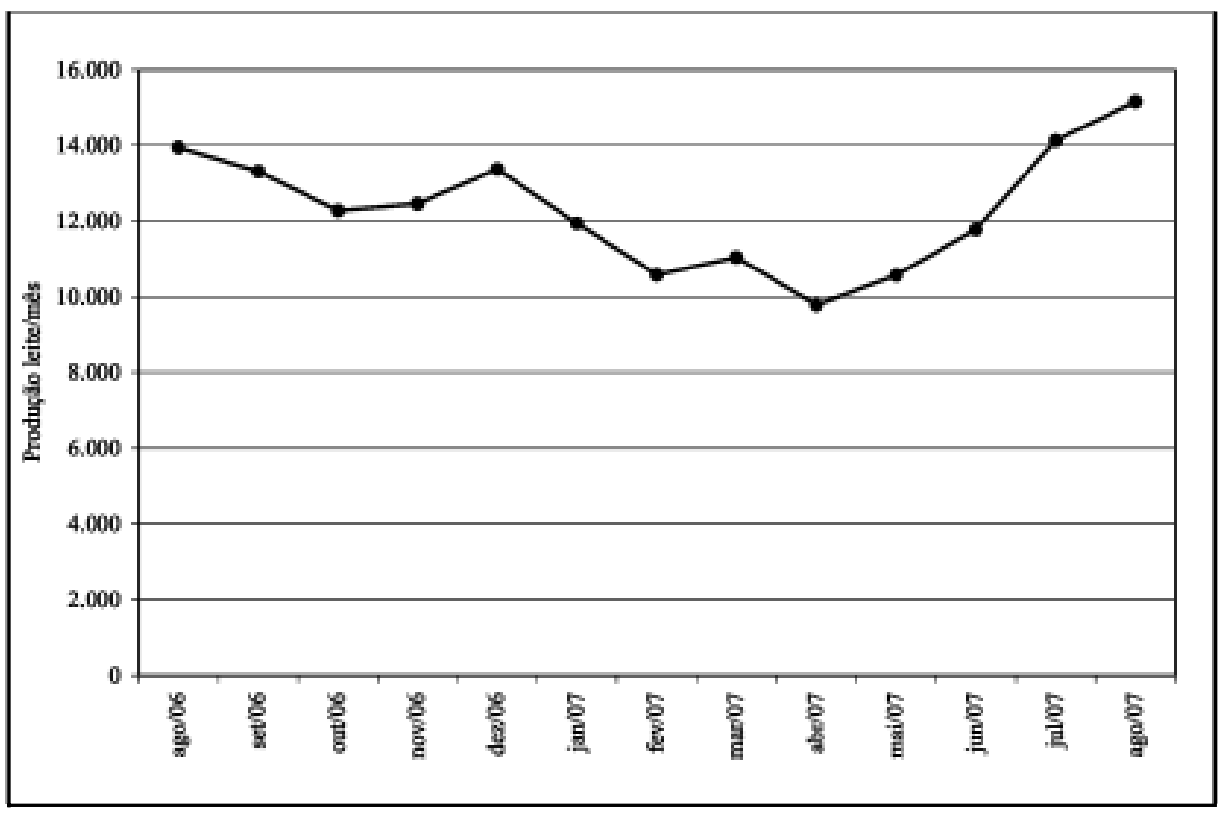

Figura 1. Médias da produção de leite mensal das propriedades selecionadas na região do Vale do Taquari, RS, no período de agosto de 2006 a agosto de 2007. 


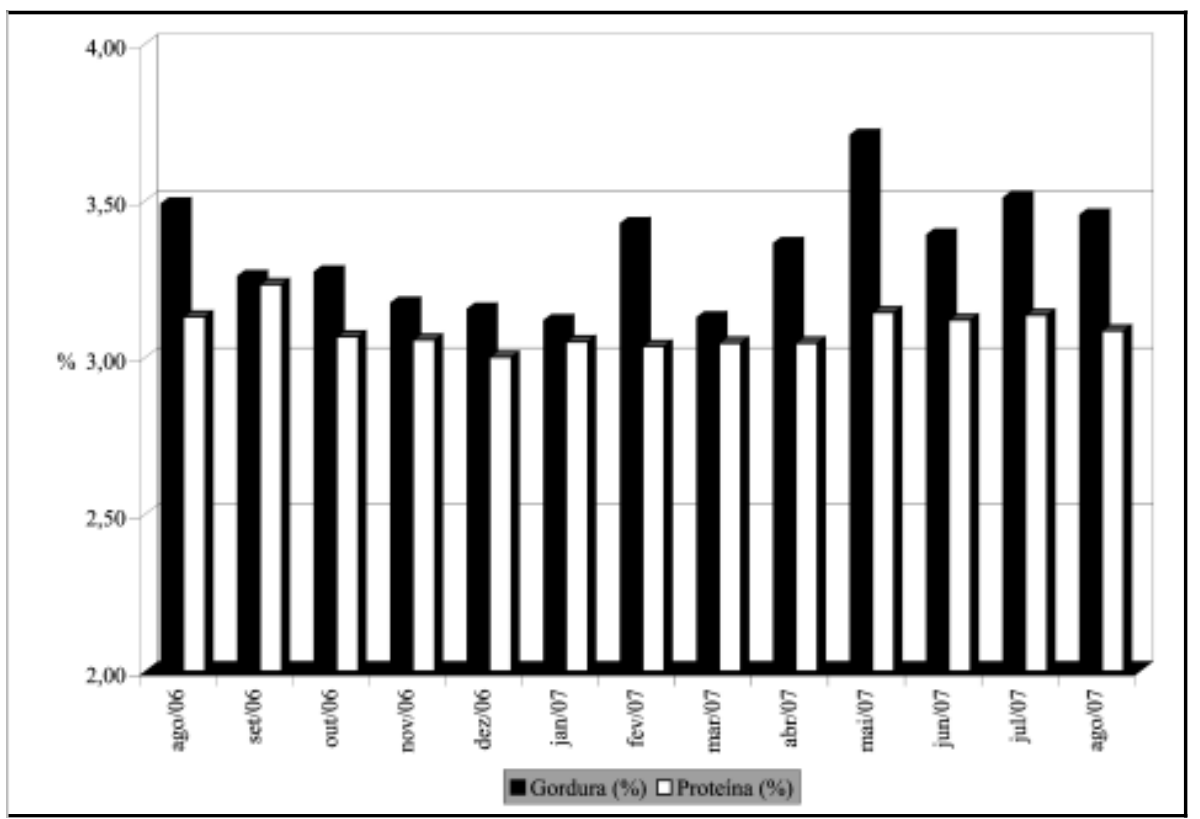

Figura 2. Teores médios dos componentes do leite das propriedades selecionadas na região do Vale do Taquari, RS, no período de agosto de 2006 a agosto de 2007.

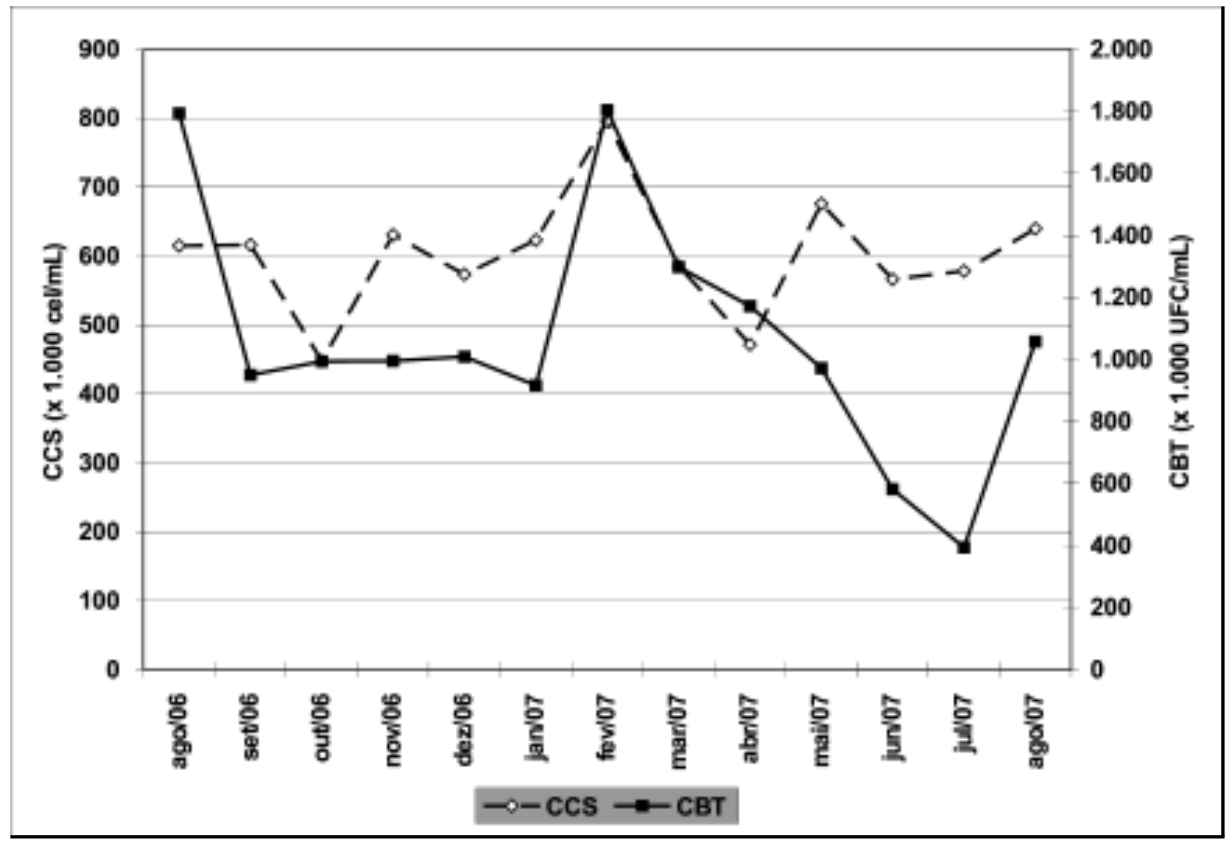

Figura 3. Médias da contagem de células somáticas (CCS) e contagem bacteriana total (CBT) do leite das propriedades selecionadas na região do Vale do Taquari, RS, no período de agosto de 2006 a agosto de 2007.

\section{RESULTADOS}

A produção de leite mensal entregue pelas propriedades selecionadas variou de 256 a 31.022 litros/mês, o que correspondeu a uma média diária de 8,4 a 1.034 litros, demonstrando a variabilidade das propriedades selecionadas. A Figura 1 compreende os valores médios de produção de leite entregue por mês das propriedades selecionadas.
Os dados analisados demonstram uma maior produção de leite nos meses de inverno, especialmente agosto de 2007 (média/produtor: 15.150L/mês). Já nos meses de fevereiro a maio, observou-se uma menor produção (média/produtor: 9.787L/mês em abril de 2007).

A média da gordura do leite das análises realizadas foi de $3,34 \%$, com uma variação de $1,6 \%$ a 
Tabela 1. Variáveis de peso de entrada, terminação, doença, origem e sexo em relação ao baixo desenvolvimento ou não dos animais no período final de terminação entre os meses de maio e agosto de 2007.

\begin{tabular}{lcc}
\hline \multicolumn{1}{c}{ Características avaliadas } & Número de amostras & \% \\
\hline Gordura $\geq 3,0 \%$ & 129 & 90,21 \\
Gordura $<3,0 \%$ & 14 & 9,79 \\
Proteína $\geq 2,9 \%$ & 132 & 92,31 \\
Proteína $<2,9 \%$ & 11 & 7,69 \\
CCS $\leq 4 \times 10^{5}$ células $/ \mathrm{mL}$ & 40 & 27,97 \\
$\mathrm{CCS}-4 \times 10^{5}$ a $7,5 \times 10^{5}$ células $/ \mathrm{mL}$ & 64 & 44,75 \\
$\mathrm{CCS}-7,5 \times 10^{5}$ a $1 \times 10^{6}$ células $/ \mathrm{mL}$ & 18 & 12,59 \\
$\mathrm{CCS} \geq 1 \times 10^{6}$ células $/ \mathrm{mL}$ & 21 & 14,69 \\
$\mathrm{CBT} \leq 3 \times 10^{5} \mathrm{UFC} / \mathrm{mL}$ & 62 & 43,36 \\
$\mathrm{CBT}-3 \times 10^{5}$ a $7,5 \times 10^{5} \mathrm{UFC} / \mathrm{mL}$ & 27 & 18,88 \\
$\mathrm{CBT}-7,5 \times 10^{5}$ a $1 \times 10^{6} \mathrm{UFC} / \mathrm{mL}$ & 12 & 8,39 \\
$\mathrm{CBT} \geq 1 \times 10^{6} \mathrm{UFC} / \mathrm{mL}$ & 42 & 29,37 \\
\hline
\end{tabular}

$5,7 \%$. O teor de gordura mais elevado foi em maio de $2007(3,71 \%)$. O teor de gordura mais baixo foi no mês de janeiro de 2007 (3,12\%).

A proteína bruta do leite apresentou média de $3,09 \%$, variando de 2,67 a 3,6\%. O maior teor de proteína foi encontrado no início da primavera, em setembro de 2006 (3,23\%), porém, após esse mês, ocorre um decréscimo nos meses seguintes, sendo o menor teor em dezembro de 2006 (3,0\%). A variação sazonal dos componentes do leite (gordura e proteína) pode ser visualizada na Figura 2.

A CCS apresentou média de $6,0 \times 10^{5}$ células $/ \mathrm{mL}$, variando de $2,0 \times 10^{3}$ a $1,6 \times 10^{6}$ células $/ \mathrm{mL}$. Foi possível observar uma variação bastante grande na CCS em determinadas épocas do ano, sendo que apresentou um pico em fevereiro de 2007 (7,96× $10^{5}$ células/ $\mathrm{mL}$ ), e o menor valor foi registrado em outubro de $2006\left(4,48 \times 10^{5}\right.$ células $\left./ \mathrm{mL}\right)$.

A CBT apresentou média de $1,07 \times 10^{6} \mathrm{UFC} /$ $\mathrm{mL}$, variando de $1,4 \times 10^{4}$ a $9,6 \times 10^{6} \mathrm{UFC} / \mathrm{mL}$. A média mais elevada foi em fevereiro de $2007\left(1,8 \times 10^{6}\right.$ $\mathrm{UFC} / \mathrm{mL})$ e a mais baixa em julho de $2007\left(3,94 \times 10^{5}\right.$ $\mathrm{UFC} / \mathrm{mL}$ ). A variação sazonal da CCS e da CBT pode ser visualizada na Figura 3.

A Tabela 1 compreende o número de amostras e a porcentagem de acordo com os limites estabelecidos pela Instrução Normativa 51, para os fatores avaliados. Conforme dados apresentados, 9,79\% e
$7,69 \%$, respectivamente, das amostras apresentaram teores de gordura e proteína abaixo dos limites estabelecidos pela IN51. Em relação à CCS, apenas 14,69\% das amostras encontravam-se acima do limite máximo estabelecido inicialmente para a Região Sul, que vigorava na época do estudo. Se fosse considerada a redução do limite máximo para $7,5 \times 10^{5}$ células $/ \mathrm{mL}$ de leite, que entrou em vigor em julho de 2008, 27,28\% das amostras estariam acima desse padrão. A contagem bacteriana total, dentre as características avaliadas, foi a mais limitante, com relação aos padrões estabelecidos pela IN51. Cerca de 29,37\% das amostras encontravam-se acima do limite máximo inicial de $1 \times 10^{6} \mathrm{UFC} / \mathrm{mL}$, e considerando-se o limite atual de $7,5 \times 10^{5} \mathrm{UFC} / \mathrm{mL}, 37,76 \%$ das amostras não se enquadrariam nos padrões previstos na legislação.

\section{DISCUSSÃO}

A maior produção de leite durante o inverno pode ser explicada pela melhor qualidade das gramíneas temperadas oferecidas nesse período. Além disso, o período de menor produção corresponde aos meses em que ocorre tradicionalmente uma escas-sez alimentar devido ao término das pastagens de verão, sendo que as pastagens de inverno ainda não se encontram aptas a sua utilização. Os dados obtidos nesse trabalho concordam com os resultados de outros estudos que também encontraram maior produção no inverno, sendo 
esta atribuída às diferentes fontes de alimentação ao longo do ano [6]. Por outro lado, a menor produção observada durante o verão pode ser decorrente da menor qualidade das for-rageiras tropicais e pelo estresse calórico sofrido pelos animais [2,9]. Outros autores encontraram maiores produções nos meses de setembro e outubro, porém também obtiveram dados de baixa produção em abril [4]. Ainda, a maior produção de leite, verificada em julho e agosto de 2007, pode ter sido impulsionada pelo elevado aumento dos preços do leite nesse perío-do. Isto fez com que os produtores, estimulados com esse aumento, aumentassem o rebanho em produção, introduzindo mais animais ao plantel e buscassem aumentar a produtividade animal, fornecendo mais alimento aos animais.

Em um estudo realizado em 2005/2006, foram analisadas amostras de leite nos rebanhos gaúchos, sendo que os teores médios mensais de gordura variam de $3,49 \%$ a 3,93\%, um pouco acima dos observados no presente estudo [3]. Os autores observaram diminuição do teor de gordura na primavera e no verão e elevação no outono, associando essas alterações aos fatores ambientais (temperatura, umidade e tipo de forrageiras disponíveis).

Com relação à proteína bruta do leite, a variação encontrada neste trabalho foi similar às variações de teores de proteína no leite observados em outro estudo, na qual as amostras variaram de $3,01 \%$ a $3,23 \%$ durante os anos de 2005/2006, com baixos teores na primavera e verão [3]. Outros autores encon-traram teores mais elevados de proteína bruta nos meses de primavera e início de verão, coincidindo com a melhoria das condições climáticas e maior oferta e qualidade das pastagens [4].

Menores valores de proteína bruta e gordura podem ser atribuídos ao menor fornecimento de concentrado e/ou uso de dietas desequilibradas pelos produtores [3]. Entre os fatores que reduzem o teor de proteína no leite estão: baixo consumo de matéria seca, falta de proteína degradável e falta de carboidratos não estruturais [7]. Entretanto, no presente trabalho não se dispõe de informações a respeito da dieta dos animais que permitam maiores inferências.

Com relação à CCS, alguns autores indicam que, em épocas quentes do ano, quando há estresse térmico, os animais possuem uma menor capacidade de resposta às injúrias, ficando mais susceptíveis às infecções no úbere, levando a um aumento das células somáticas. Além disso, os animais podem reduzir o consumo de alimentos, produzindo menos leite e aumentando, dessa forma, a concentração de células somáticas no leite [11]. No presente estudo, o aumento da CCS nos períodos quentes de alguns produtores foi superior a média dos mesmos ao longo do ano. Possivelmente, esse aumento esteja relacionado com surtos de mastite ocorridos nesse período.

A CBT apresentou ampla variação ao longo do ano, o que também foi verificado em outros estudos no RS [3]. Com relação à IN51, observou-se que um número grande de amostras não se enquadrou nos padrões exigidos pela legislação, sendo o fator limitante a CBT. Isso indica que é necessário um maior trabalho dos profissionais que atuam no setor, a fim de estabelecer melhores condições higiênico-sanitárias para obtenção de uma matéria prima de qualidade. Procedimentos de higiene na obtenção do leite como: manejo de ordenha adequado, limpeza dos equipamentos de ordenha e refrigeração e refrigeração adequada, são importantes fatores para redução da contagem bacteriana do leite.

\section{CONCLUSÃO}

É possível concluir que os teores da composição química do leite variaram em função dos meses do ano, relacionados, possivelmente, às variações da qualidade dos alimentos e ao manejo nutricional adotado por cada produtor. A composição química e a contagem de células somáticas do leite analisado, na região do Vale do Taquari, demonstraram a boa qualidade da matéria prima quando comparados aos padrões da IN51. A contagem bacteriana total foi o fator limitante para a adequação do leite à legislação.

\section{REFERÊNCIAS}

1 Borges K.A. 2007. Mastite bacteriana bovina e a importância da contagem de células somáticas na avaliação da qualidade do leite. 61f. Porto Alegre, RS. Monografia de conclusão de curso (Graduação em Medicina Veterinária) - Faculdade de Medicina Veterinária, Universidade Federal do Rio Grande do Sul.

2 Corsi M. \& Martha Jr. G.B. 1998. Manejo de pastagens para produção de carne e leite. In: Peixoto A.M., Moura J.C. \& Faria V.P. (Eds). Manejo de pastagens de Tifton, Coastcross e Estrela. Piracicaba: Escola Superior de Agricultura Luiz de Queiroz, 296p. 
3 Dürr J.W., Moro D.V., Rheinhemer, V. \& Tomazi T. 2006. Estado atual da qualidade do leite no Rio Grande do Sul. In: Mesquita A.J., Dürr J.W. \& Coelho K.O. (Eds). Perspectivas e avanços da qualidade do leite no Brasil. Passo Fundo: Editora Universidade de Passo Fundo, pp.83-94.

4 Martins P.R.G., Fischer V., Ribeiro M.E.R., Stumpf Jr. W., Silva C.A. \& Zanela M.B. 2006. Produção e qualidade do leite na bacia leiteira de Pelotas-RS em diferentes meses do ano. Ciência Rural. 36: 209-214.

5 Ministério da Agricultura, Pecuária e Abastecimento (MAPA). 2002. Departamento Instrução Normativa n51: Regulamentos Técnicos de Produção, Identidade e Qualidade do Leite. Diário Oficial da União, Brasília. Seção 1, p.13.

6 Noro G., González F.H.D., Campos R. \& Dürr J.W. 2006. Fatores ambientais que afetam a produção e a composição do leite em rebanhos assistidos por cooperativas no Rio Grande do Sul. Revista Brasileira de Zootecnia. 35: 1129-1135.

7 Peres J.R. 2001. O leite como ferramenta de monitoramento nutricional. In: Gonzales F.H.D., Dürr J.W. \& Fontaneli R.S. (Eds). Uso do leite para monitorar a nutrição e metabolismo de vacas leiteiras. Porto Alegre: Universidade Federal do Rio Grande do Sul, pp.29-43.

8 Philpot N. \& Nickerson S.C. 2002. A importância da qualidade do leite. In: Vencendo a Luta Contra a Mastite. São Paulo: Milkbizz, pp.154-159.

9 Ray D.E., Halbach T.J. \& Armstrong D.V. 1992. Season and lactation number effects on milk production and reproduction of dairy cows in Arizona. Journal of Dairy Science. 75: 2976-2983.

10 Reichert S. 2007. Fatores determinantes nos teores de gordura e proteína do leite. 2007. 30f. Porto Alegre, RS. Monografia de conclusão de curso (Graduação em Medicina Veterinária) - Faculdade de Medicina Veterinária, Universidade Federal do Rio Grande do Sul.

11 Souza G.N., Silva M.R., Sobrinho F.S., Coelho R.O., Brito M.A.V.P. \& Brito J.R.F. 2006. Efeito da temperatura e do tempo de Armazenamento sobre a contagem de células somáticas do leite. Arquivo Brasileiro de Medicina Veterinária e Zootecnia. 57: 830-834.

12 Zanela M.B., Fischer V. \& Ribeiro M.E.R. 2006. Qualidade do leite em sistemas de produção na região Sul do Rio Grande do Sul. Pesquisa Agropecuária Brasileira. 41: 153-159. 